\title{
Direct Deposition of Bamboo-Like Carbon Nanotubes on Copper Substrates by Sulfur-Assisted HFCVD
}

\author{
Sri Lakshmi Katar, ${ }^{1,2}$ Adolfo González-Berríos, ${ }^{3}$ Joel De Jesus, ${ }^{3}$ Brad Weiner, $^{1,2}$ and Gerardo Morell ${ }^{1,3}$ \\ ${ }^{1}$ Institute for Functional Nanomaterials, University of Puerto Rico, P.O. Box 23343, San Juan, PR 00931, USA \\ ${ }^{2}$ Department of Chemistry, University of Puerto Rico, P.O. Box 23343, San Juan, PR 00931, USA \\ ${ }^{3}$ Department of Physics, University of Puerto Rico, P.O. Box 23343, San Juan, PR 00931, USA
}

Correspondence should be addressed to Sri Lakshmi Katar, srilakshmikatar@yahoo.com

Received 28 May 2008; Accepted 21 October 2008

Recommended by Alan K. T. Lau

\begin{abstract}
Films of bamboo-like carbon nanotubes (BCNTs) were grown directly on copper substrates by sulfur-assisted hot filament chemical vapor deposition (HFCVD). The effects of substrate temperature and growth time over the BCNT structure were investigated. The films were characterized by scanning electron microscopy (SEM), Raman spectroscopy (RS), transmission electron microscopy (TEM), X-ray photoelectron spectroscopy (XPS), and electron field emission (EFE) studies. SEM and Raman characterization indicate a transition from the growth of microcrystalline diamond to the growth of a dense entangled network of carbon nanotubes or fibers as the substrate temperature is increased from 400 to $900^{\circ} \mathrm{C}$ that is accounted for by the base growth model. TEM images show that the nanotubes have regular arrays of nanocavities. These BCNTs show good electron field emission properties as other carbon films.
\end{abstract}

Copyright (C) 2008 Sri Lakshmi Katar et al. This is an open access article distributed under the Creative Commons Attribution License, which permits unrestricted use, distribution, and reproduction in any medium, provided the original work is properly cited.

\section{INTRODUCTION}

Diamond deposition on copper substrates was studied back in 1992, morphology of both the as-plated copper/diamond matrix and the film that resulted after further CVD diamond deposition were reported [1]. The influence of bias-enhanced nucleation (BEN) on polycrystalline copper substrates was reported [2]. Copper exhibits a good lattice match with diamond; therefore, this material has been studied previously $[3,4]$. Copper does not form carbide but instead maintains a stable graphitic surface carbon [2]. When the diamondscratched $\mathrm{Cu}$ substrates were molten, owing to insolubility of $\mathrm{C}$ in $\mathrm{Cu}$, a carbon-rich surface layer was formed [5]. Freestanding diamond films can be prepared using copper substrate by CVD; thin films $(\sim 10 \mu \mathrm{m})$ are obtained using a two-step growth method for stress relief. Thicker films $(>20 \mu \mathrm{m})$ can be prepared through direct deposition [6]. The growth of graphitic layers becomes more and more distorted when going away from the copper surface and finally, when a critical size corresponding to 5-6 layers is reached, diamond nucleation and growth takes place [7]. A strong interaction of the graphite layer with the copper surface is reported in a diamond growth characterization study using Auger and X-ray photoelectron spectroscopy. High-resolution electron microscopy results indicate that there exists a graphite/amorphous carbon intermediate layer between CVD diamond and its $\mathrm{Cu}$ substrate [8]. Ab initio calculations show that diamond crystallites can be grown on polycrystalline copper up to 20 micrometer in thickness with the preferable orientation of $\langle 111\rangle$ [9]. In our laboratory, we are engaged in an effort to grow diamond films on copper substrates for lithium rechargeable battery applications [10]. While studying the growth properties of these diamond films, we found a dense cluster of bamboo-like carbon nanotubes.

Carbon nanotubes (CNTs) have been of great interest to scientists and industrial communities due to their unique properties and diverse applications such as in nanoelectronics [11-13], scanning probes [14], supercapacitors [1519], and field emitters [20-22]. Recently, carbon nanotubes with special structures such as bamboo-shaped [23, 24], octopus [24], fish-bone [25], and coils [26], which are different from the conventional straight tubes, have attracted immense interest. As the most common member of this 


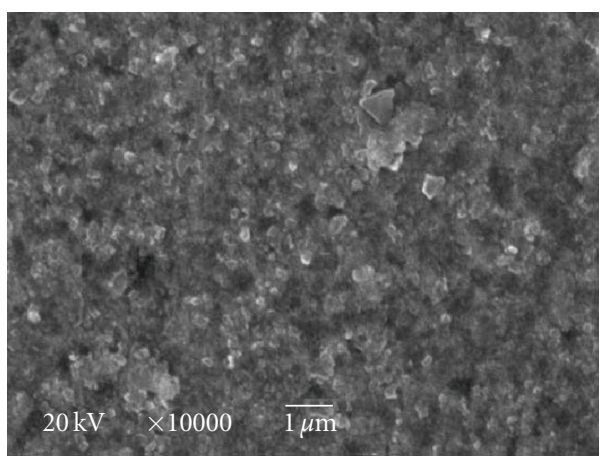

(a)

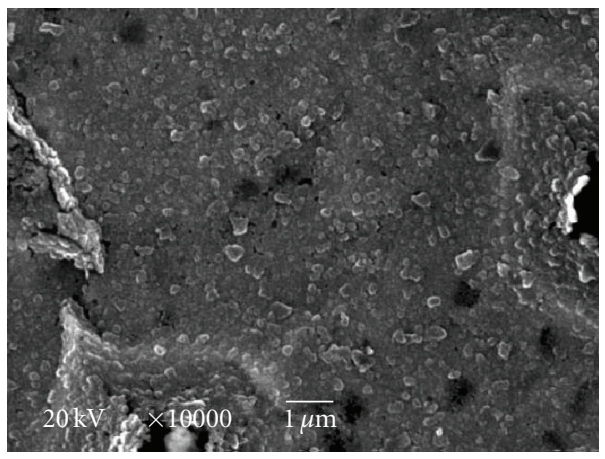

(c)

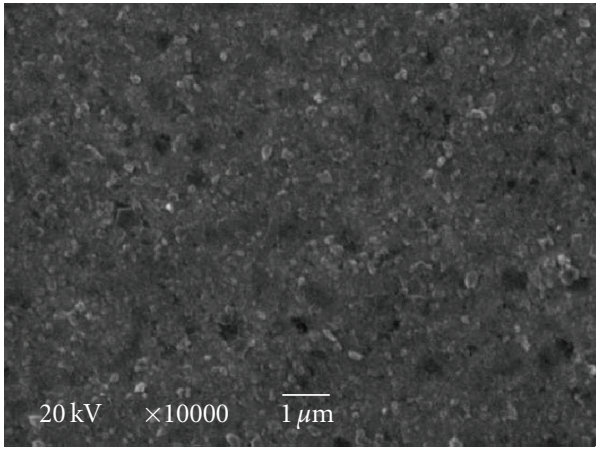

(b)

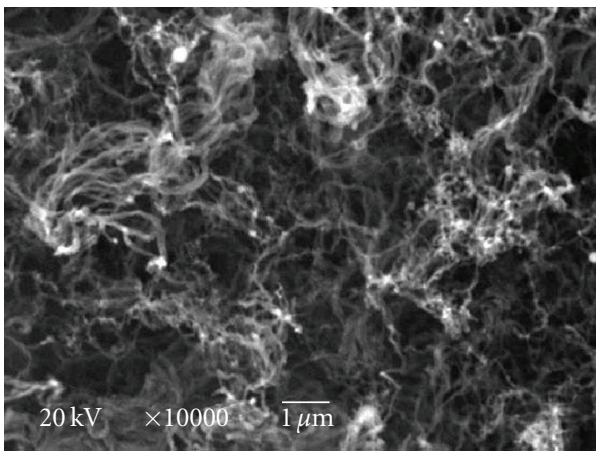

(d)

Figure 1: SEM micrograph of the BCNT directly deposited on $\mathrm{Cu}$ at different temperatures showing (a) $400^{\circ} \mathrm{C}, 2$ hours; (b) $500^{\circ} \mathrm{C}, 5$ minutes; (c) $700^{\circ} \mathrm{C}, 5$ minutes; (d) $900^{\circ} \mathrm{C}, 15$ minutes.

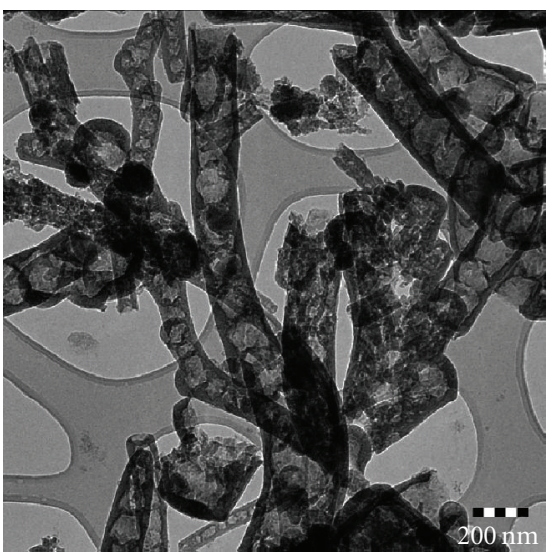

(a)

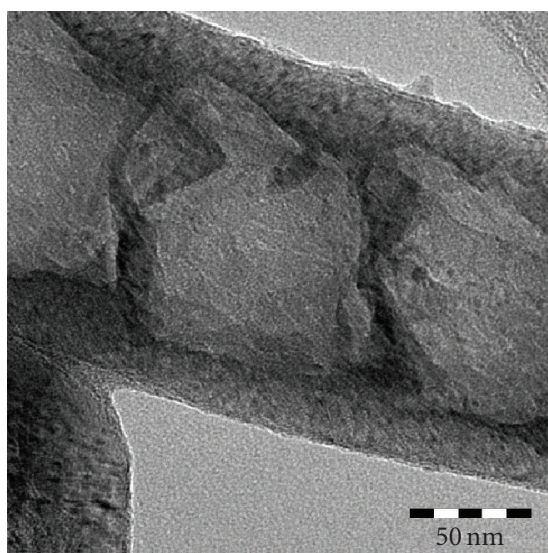

(b)

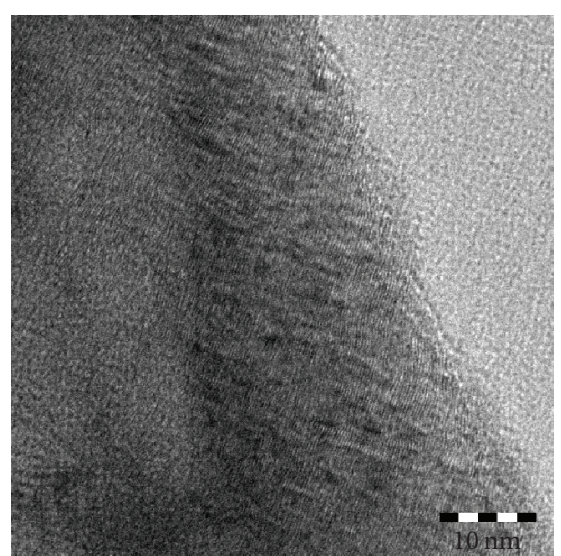

(c)

FIGURE 2: TEM images of the BCNT directly deposited on Cu showing (a) bamboo-like carbon nanotubes, (b) high-resolution image of the nanocavities, and (c) graphitic sidewalls of a nanocavity.

family, bamboo-shaped CNTs, consisting of many separated hollow compartments, [24-26], have been investigated to explore their unique structure-associated properties. Several studies on the synthesis of these periodic structures were reported using hot filament chemical vapor deposition [27], direct current plasma-enhanced hot filament chemical vapor deposition method [28], and microwave plasma chemical vapor deposition system [29, 30]. The sulfur- and phosphorus-doped diamond films were grown epitaxially by a quartz tube-type microwave-assisted plasma chemical vapor deposition method [31]. Another group reported the growth of BCNTs using nickel electroplated thin copper 


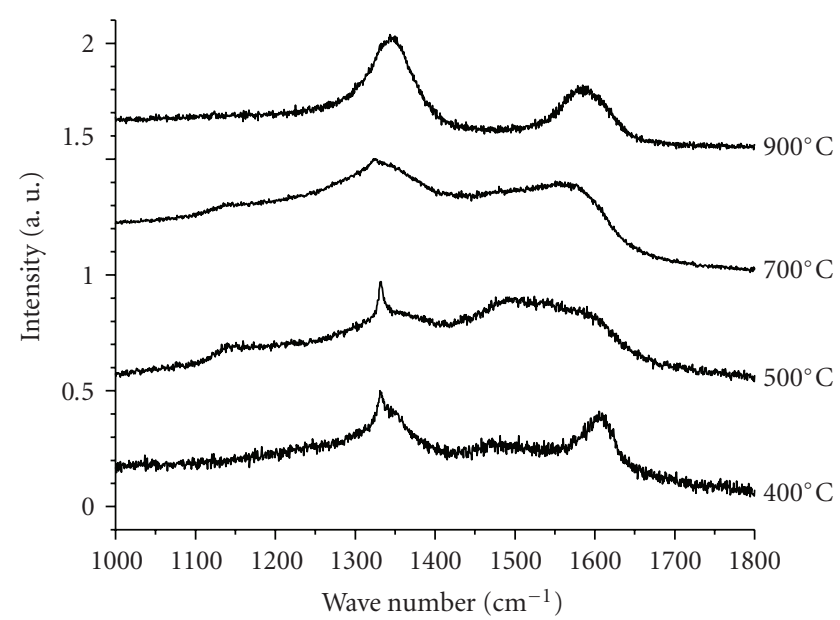

Figure 3: Raman spectra of carbon films grown at different temperatures showing the transition from microcrystalline diamond to BCNTs.

foils [22]. It has been found that these structures are stable. Bamboo-like carbon nanostructures resemble zigzag carbon nanotubes capped with a plain graphene sheet [32].

Recently, we have synthesized multiwalled carbon nanotubes and nanofibres on molybdenum substrates [33]. Carbon-based films have been considered as potential materials for field emission (FE) devices, such as FE displays and micro X-ray sources because of their unique properties and characteristics: relatively low-threshold field, robustness, chemical inertness, radiation hardness, and ease of production. Although available field emission data from structures similar to the ones reported in this paper are not abundant, the ones reported indicate that these bamboolike structures show good field emission properties [34, 35]. While investigating the diamond film growth on copper substrates in greater detail, we have found a mass of bamboo-like carbon nanotubes, which can be prepared at a temperature of $900^{\circ} \mathrm{C}$ without depositing a catalyst layer on the substrate prior to carbon film deposition. In this paper, we report the growth of these periodic structures at different deposition temperatures and times, the copper substrate and sulfur doping effect the structure of the films prepared by hot filament chemical vapor deposition.

\section{EXPERIMENTAL}

The carbon films deposited on copper substrates used in this study were grown in a custom-made HFCVD chamber which has been previously described in detail elsewhere [36]. Tungsten wire (99.95\% pure, $0.5 \mathrm{~mm}$ diameter) was wound as a helical spring filament in the HFCVD. Before the thin films deposition, the tungsten filament was carburized. For this, we pumped down the CVD chamber to $8 \times$ $10^{-6}$ mbar $\left(6.0 \times 10^{-6}\right.$ torr $)$ and then filled it with a mixture of $2.0 \% \mathrm{CH}_{4}, 98.0 \% \mathrm{H}_{2}$ with $500 \mathrm{ppm}$ of $\mathrm{H}_{2} \mathrm{~S}$. Maintaining the combined flow of gases at $100 \mathrm{sccm}$, and a pressure of 20 torr, we kept a constant current of 20 amps through the tungsten wire, for 8 hours. Starting the carburization process, the voltage across the filament was $7.7 \mathrm{~V}$, indicating a low resistance for pure tungsten, but as the time progressed, the voltage increased, reaching $17.0 \mathrm{~V}$ after 8 hours.

Polycrystalline copper substrates $(99.9 \%$ pure, $0.5 \mathrm{~mm}$ thick, $14 \mathrm{~mm}$ disk diameter) were hand polished with 600 grit sandpaper on both sides to make them flat. One side was then further polished with 1000, 1500, and 2000 grit sandpaper to smooth the surface. The last step of the polishing was made with diamond powder ( $<1$ micron particle size) to achieve a mirror-like surface and for diamond scratching and seeding to enhance the nucleation. Before the diamond powder polishing, the substrates had a natural copper color, and after the powder polishing, the substrates looked darker. The substrates were then cleaned in an ultrasonic bath with 2-propanol for 15 minutes, dried with helium, and inserted in the HFCVD chamber on top of a molybdenum substrate holder.

Prior to each deposition, we pumped down the CVD chamber to $8 \times 10^{-6} \mathrm{mbar}\left(6.0 \times 10^{-6}\right.$ torr $)$ and then introduced the gases. For all the samples discussed in this paper, we kept constant the gas mixture of $2.0 \% \mathrm{CH}_{4}, 98 \% \mathrm{H}_{2}$ with $500 \mathrm{ppm}$ of $\mathrm{H}_{2} \mathrm{~S}$, the combined flow of the gases to $100 \mathrm{sccm}$, the deposition pressure at 20 torr, the filament temperature at $\sim 2500^{\circ} \mathrm{C}$, and the filament-substrate distance to $8 \mathrm{~mm}$. The only parameters changed were the substrate temperature and the deposition time. We grew samples at $500^{\circ} \mathrm{C}$ for 2 hours, at $700^{\circ} \mathrm{C}$ and $800^{\circ} \mathrm{C}$ for 5 minutes, and at $900^{\circ} \mathrm{C}$ for 15 minutes. The deposition time was selected in order to achieve a film that covered the whole substrate that did not experience peeling or delamination from the copper substrate for the selected substrate temperature.

Scanning electron microscopy using a JEOL model 35 CF microscope revealed the surface morphology. Raman spectroscopy is used to analyze the structure. The Raman spectra were recorded using a triple monochromator (ISA J-Y Model T64000) using the $514.5 \mathrm{~nm}$ line of Ar laser. The spectra were recorded using an $80 \mathrm{x}$ objective, and the probed area was of $1-2 \mu \mathrm{m}^{2}$. The power on the sample was kept below $10 \mathrm{~mW}$ to avoid damage. Silicon was used to calibrate the Raman peak position. A Carl Zeiss TEM LEO 922 transmission electron microscope operating at $200 \mathrm{kV}$ was used to observe the morphology and microstructure of the BCNT samples.

The sample was scraped from the copper disk and mixed in water to make a suspension. A drop of the suspension was spin coated on the copper grids covered with a formvar carbon film. A JEOL 3010 high-resolution transmission electron microscope operating at $300 \mathrm{kV}$ was used to observe the morphology and microstructure of the BCNTs samples.

Field emission I-V characteristics were measured in a custom-made system, described in detail elsewhere [37]. Briefly, a diode configuration is used, in which a molybdenum rod of $3 \mathrm{~mm}$ diameter (area: $0.071 \mathrm{~cm}^{2}$ ) serves as the anode. Voltage is applied using a Stanford Research Systems PS350 power supply. The emitted current is measured with a Keithley 6517A electrometer. For the configuration employed, the macroscopic surface electric field $\left(E_{S}\right)$ on the sample (i.e., cathode) can be estimated accurately by $E_{S}=V / d_{\text {CA }}$, where $V$ is the voltage applied to the anode 


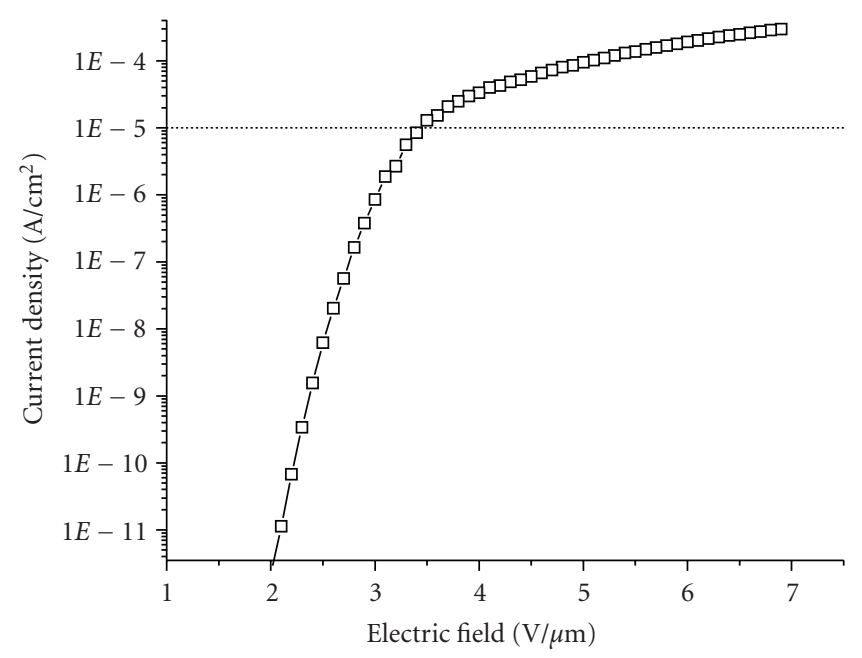

(a)

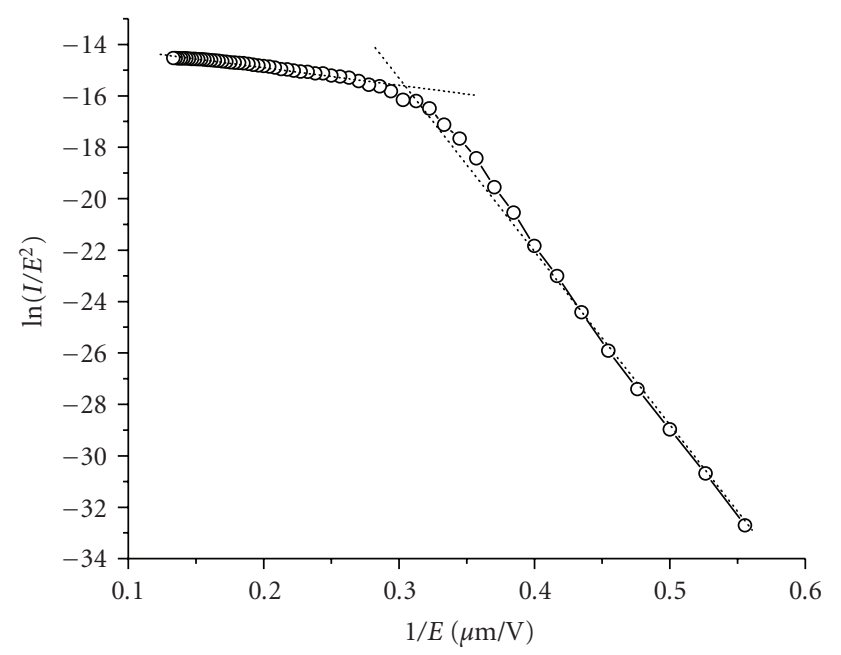

(c)

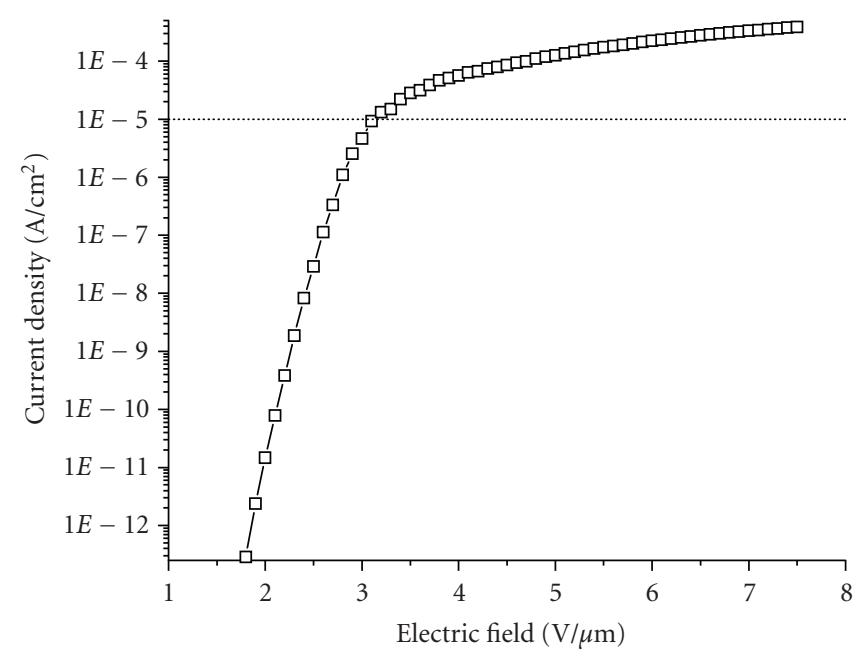

(b)

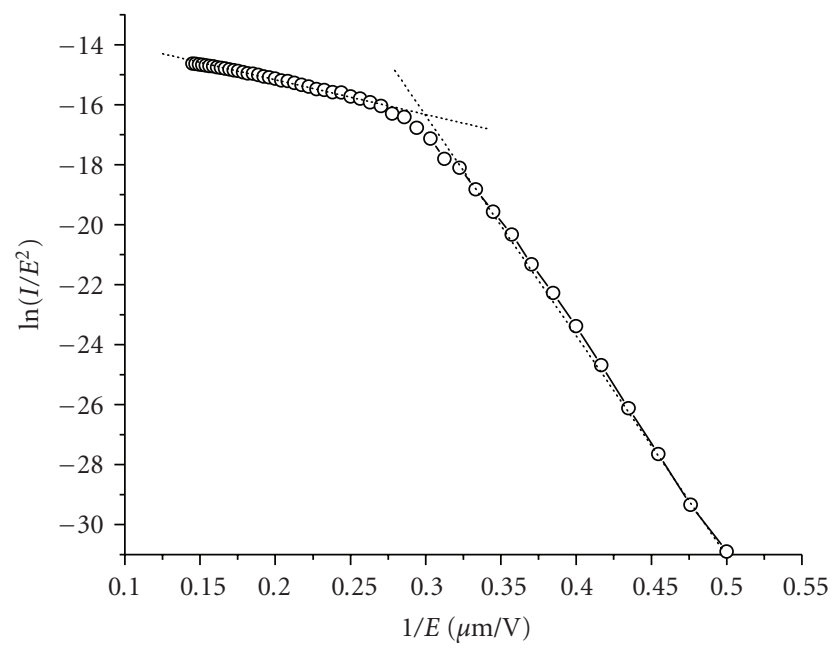

(d)

FIgURE 4: (a) and (b) Field emission plots of two samples of BCNTs showing the behavior of the current density as a function of electric field, (c) and (d) the corresponding Fowler-Nordheim plots revealing two distinct slopes.

and $d_{\mathrm{CA}}$ is the distance between the anode and the cathode [38]. All the measurements were taken at $d_{\mathrm{CA}}=100 \pm$ $2 \mu \mathrm{m}$, and at a pressure of $1-2 \times 10^{-7}$ Torr $(1.3-2.7 \times$ $10^{-7}$ mbar). Currents lower than $1 \times 10^{-12}$ A were considered at the background noise level. The current density was calculated by dividing the current over the area of the sample subjected to $E_{S}=V / d_{\mathrm{CA}}$, which, in our specific configuration, is well approximated by using the area of the anode $\left(0.071 \mathrm{~cm}^{2}\right)$ [38]. The turn-on field $\left(E_{t}\right)$ was defined as the electric field necessary to emit a current density of $10 \mu \mathrm{A} / \mathrm{cm}^{2}$. Each data point in the I-V curves is the average of 8 measurements taken 250 milliseconds apart. For data acquisition, a custom Lab View (National Instruments) program was developed. As a measure of precaution to avoid the influence of displacement or charging current in the field-emitted current, specifically in currents smaller than $1 \times 10^{-11} \mathrm{~A}$, a delay of 4 seconds between the change in voltage and the data acquisition was employed.

\section{RESULTS AND DISCUSSIONS}

Scanning electron microscopy images (Figure 1) show significant qualitative differences between films grown below and at $900^{\circ} \mathrm{C}$. The films deposited on copper at 400 , 500,700 , and $800^{\circ} \mathrm{C}$ are composed of submicron particles. The films grew faster as the substrate temperature was increased, to the point that films deposited at $700^{\circ} \mathrm{C}$ are delaminated due to thickness. The films deposited at $900^{\circ} \mathrm{C}$ for 15 minutes show entangled clusters of nanotubes or nanofiber structures that were analyzed in more detail by TEM (Figure 2). As shown in Figures 2(a) and 2(b) with different magnifications, the films grown at $900^{\circ} \mathrm{C}$ are composed of bamboo-like carbon nanotubes (BCNTs) with diameters ranging from $50-100 \mathrm{~nm}$ and variable lengths. They contain nanocavities that are stacked one over the other with closed walls consisting of a number of graphene layers (Figure 3(c)). 
The energy dispersive X-ray analyses (EDS) reveal the presence of sulfur and carbon in the bamboo-like carbon nanotubes clusters. These results are confirmed by the results from X-ray photoelectron spectroscopy, which indicate the carbon and sulfur peaks. The XPS results revealed a sharp C 1 s peak at $284.4 \mathrm{eV}$ and an S 2p peak at $165.9 \mathrm{eV}$. The atomic concentrations from XPS data showed that the sample contains $98.4 \%$ carbon, $1.44 \%$ oxygen, and $0.15 \%$ sulfur.

The addition of trace amounts of sulfur, in the form of hydrogen sulfide, to the diamond chemical vapor deposition reaction produces profound changes in the gas phase chemistry and the surface chemistry. We have reported a four-fold increase in the deposition rate, from 0.1 to $0.4 \mu \mathrm{m}$ with $500 \mathrm{ppm}$ of hydrogen sulfide [39], and the formation of BCNTs instead of nanocrystalline diamond films as we change the substrate from $\mathrm{Mo}$ to $\mathrm{Cu}[10]$. In the gas phase, $\mathrm{H}_{2} \mathrm{~S}$ leads to the formation of $\mathrm{CS}$ in the heat-activated volume around the filament, which turns back into $\mathrm{H}_{2} \mathrm{~S}$ in the cooler region above the substrate, while leaving $\mathrm{C}$ atoms deposited on the substrate surface to form diamond [40]. This process results in a new C-transport mechanism to the substrate. In addition, at the growing surface, sulfur acts as a cross-linker that promotes the formation of graphitic bonds at the growing surface before it is released back to the vapor phase [41]. Moreover, sulfur has the effect of lowering the melting point of the $\mathrm{Cu}$ substrate [42] rendering it in a quasiliquid state at the surface, thus enabling its catalytic activity for the growth of BCNTs at temperatures falling short from the melting point of bulk $\mathrm{Cu}$. Hence, the formation of BCNTs by HFCVD at $900^{\circ} \mathrm{C}$ is directly related to the presence of sulfur and the use of $\mathrm{Cu}$ substrates.

Raman spectra of the all the films were recorded at four different places on the substrate to confirm the homogeneity and reproducibility of the results. The Raman spectra (Figure 3) show the evolution of carbon bonding nature for the films deposited as a function of substrate temperature at $400,500,700,900^{\circ} \mathrm{C}$. The results agree with those found by SEM and described above. All of the films grown below $900^{\circ} \mathrm{C}$ have the signature of diamond and nanocomposite carbon in different proportions. The Raman peak at around $1332 \mathrm{~cm}^{-1}$ corresponds to the longitudinal optical (LO) mode of diamond and is characteristic of microcrystalline $\mathrm{sp}^{3}$-bonded C. The peak around $1580 \mathrm{~cm}^{-1}$ corresponds to the Raman active $E_{2 \mathrm{~g}}$ mode in graphite and is called the Gband [43]. The peak at around $1360 \mathrm{~cm}^{-1}$ is ascribed to the Raman inactive $A 1_{g}$ mode frequency and is called the $\mathrm{D}$ band. A breakdown in selection rules due to disorder in the graphite structure (defects, curved graphite sheets, dislocations, and lattice distortions) renders it to be active. These two peaks are characteristic of graphitic structures [44]. For the films under study, the D-band is larger than the G-band, indicating that they contain trigonally bonded carbon with a large degree of disorder in relation to crystalline graphite [5, 45-48]. The analysis of the Raman spectra indicates that disorder in the graphitic structures increases as the substrate temperature increases, while the diamond component diminishes and finally disappears for films grown at $900^{\circ} \mathrm{C}$, which corresponds to BCNTs. The breathing mode peak at $190.5 \mathrm{~cm}^{-1}$ was not observed, as expected for BCNTs.
The above-described characterization indicates a transition from a growth of microcrystalline diamond to the growth of a dense entangled network of carbon nanotubes or fibers as the substrate temperature is increased from 400 to $900^{\circ} \mathrm{C}$, approaching the melting point of copper $\left(1085^{\circ} \mathrm{C}\right)$ within $14 \%$ in absolute scale due to the active role of surface copper atoms. Nanocrystalline diamond is instead obtained at $900^{\circ} \mathrm{C}$ when molybdenum is employed as substrate, for which the temperature stays $63 \%$ below its melting point in absolute scale. Due to the capillary action of the nanotubes and the variation of the surface tension of the copper particles, which act as a catalyst during growth, the nanotubes grow with a regular bamboo-like shape. These results indicate that the underlying growth mechanism can be described by the base growth model [49]. Assuming that this model is operating in this case, the highly movable $\mathrm{Cu}$ particles on the surface act as catalysts as the $\mathrm{Cu}$ substrate temperature approaches its melting point $\left(1084^{\circ} \mathrm{C}\right)$. The base growth model is also consistent with the lack of metal particle filling the nanocavities.

\section{FIELD EMISSION PROPERTIES}

These BCNTs show field emission properties that indicate the existence of a good interface between the substrate and the BCNTs, which formed by direct deposition (i.e., no catalyst or buffer layer). For reproducibility of the results, we have chosen two BCNT samples (a, b) deposited at $900^{\circ} \mathrm{C}$ for this study. The turn-on field was estimated to be around $3.43 \mathrm{~V} / \mu \mathrm{m}$ for one sample (see Figure $4(\mathrm{a})$ ) and around $3.35 \mathrm{~V} / \mu \mathrm{m}$ for the second sample (see Figure 4(b)). These turn-on fields are slightly above those reported by Ding et al. [34] and Srivastava et al. [50] on samples containing bamboo-like carbon nanotubes $(1.4 \mathrm{~V} / \mu \mathrm{m}$ and about $1.5 \mathrm{~V} / \mu \mathrm{m}$, resp.) [51] and they are similar to turnon fields reported from nonaligned carbon multiwalled nanotubes by Sveningsson et al. [52]. The Fowler-Nordheim (F-N) plots (see Figures 4(c) and 4(d)) show two distinctive linear regions: one on the high-electric field region (located at the left side of the plot) and the other on the low-electric field region (located at the right side of the plot). These two regions featured in F-N plots appear in field emission data from various materials, including diamond-like carbon films and carbon nanotubes [33, 37]. It was shown by Xu et al. [53] that this feature is not caused by adsorbates and that it could be caused by space charge effects [54]. However, Liao et al. [55] while studying field emission from diamond films proposed that this feature is caused by the quantum tunneling of the electrons through multiple barriers caused by the presence of different materials or structures. The F-N plots in this paper indicate that such tunneling through multiple barriers does occur in the BCNTs films, enhancing in this way the electron field emission properties of the films by providing more than one channel for electron tunneling [56].

\section{CONCLUSIONS}

HFCVD was employed to synthesize films of BCNTs directly on copper substrates without any intentional catalysts. The 
structural and compositional characterizations indicate that carbon films deposited on copper undergo a transition from microcrystalline diamond to a dense entangled network of carbon nanotubes or fibers as the substrate temperature is increased from 400 to $900^{\circ} \mathrm{C}$. This result was ascribed to the active role of surface copper atoms as the substrate temperature approaches the melting point of copper $\left(1085^{\circ} \mathrm{C}\right)$ within $14 \%$ in absolute temperature scale. The BCNTs have regular arrays of nanocavities and their growth is consistent with the base growth model. These BCNTs appear to have good electrical contact to the substrate from the fact that they show excellent electron field emission properties similar to other carbon films grown on carbide-forming substrates.

\section{ACKNOWLEDGMENTS}

This research project is being carried out under the auspices of the Institute for Functional Nanomaterials (NSF Grant no. 0701525). This research was also supported in part by NASA Training Grant NNG05GG78H (PR Space Grant) and NASA Cooperative Agreements NNX07AO30A and NNX08AB12A (PR NASA EPSCoR). The authors gratefully acknowledge Dr. R. Katiyar and W. Perez (Raman spectroscopy) and Oscar Resto for the high-resolution transmission electron microscopy.

\section{REFERENCES}

[1] R. Ramesham, F. M. Rose, and A. Allerman, "Selective diamond seed deposition using electroplated copper," Diamond and Related Materials, vol. 1, no. 8, pp. 907-910, 1992.

[2] S. D. Wolter, B. R. Stoner, and J. T. Glass, "The effect of substrate material on bias-enhanced diamond nucleation," Diamond and Related Materials, vol. 3, no. 9, pp. 1188-1195, 1994.

[3] C.-M. Niu, G. Tsagaropoulos, J. Baglio, K. Dwight, and A. Wold, "Nucleation and growth of diamond on $\mathrm{Si}, \mathrm{Cu}$, and $\mathrm{Au}$ substrates," Journal of Solid State Chemistry, vol. 91, no. 1, pp. 47-56, 1991.

[4] J. Narayan, V. P. Godbole, G. Matera, and R. K. Singh, "Enhancement of nucleation and adhesion of diamond films on copper, stainless steel, and silicon substrates," Journal of Applied Physics, vol. 71, no. 2, pp. 966-971, 1992.

[5] M. Ece, B. Oral, and J. Patscheider, "Nucleation and growth of diamond films on Mo and Cu substrates," Diamond and Related Materials, vol. 5, no. 3-5, pp. 211-216, 1996.

[6] Q. H. Fan, J. Gracio, and E. Pereira, "Free-standing diamond film preparation using copper substrate," Diamond and Related Materials, vol. 6, no. 2-4, pp. 422-425, 1997.

[7] L. Constant and F. Le Normand, "AES and XPS observations of HFCVD diamond deposition on monocrystalline (111) copper," Diamond and Related Materials, vol. 6, no. 5-7, pp. 664-667, 1997.

[8] N. Jiang, L. C. Wang, J. H. Won, et al., "Interfacial analysis of CVD diamond on copper substrates," Diamond and Related Materials, vol. 6, no. 5-7, pp. 743-746, 1997.

[9] V. G. Zavodinsky, "Density functional study of diamond epitaxy on the (111) and (100) surfaces of copper," Diamond and Related Materials, vol. 15, no. 9, pp. 1201-1205, 2006.

[10] S. L. Katar, J. De Jesus, B. R. Weiner, and G. Morell, "Films of bamboo-like carbon nanotubes as electrode material for rechargeable lithium batteries," Journal of the Electrochemical Society, vol. 155, no. 2, pp. A125-A128, 2008.

[11] P. G. Collins, A. Zettl, H. Bando, A. Thess, and R. E. Smalley, "Nanotube nanodevice," Science, vol. 278, no. 5335, pp. 100103, 1997.

[12] R. Martel, T. Schmidt, H. R. Shea, T. Hertel, and P. Avouris, "Single- and multi-wall carbon nanotube field-effect transistors," Applied Physics Letters, vol. 73, no. 17, pp. 2447-2449, 1998.

[13] L. Roschier, J. Penttilä, M. Martin, et al., "Single-electron transistor made of multiwalled carbon nanotube using scanning probe manipulation," Applied Physics Letters, vol. 75, no. 5, pp. 728-730, 1999.

[14] H. Dai, J. H. Hafner, A. G. Rinzler, D. T. Colbert, and R. E. Smalley, "Nanotubes as nanoprobes in scanning probe microscopy," Nature, vol. 384, no. 6605, pp. 147-150, 1996.

[15] G. Che, B. B. Lakshmi, E. R. Fisher, and C. R. Martin, "Carbon nanotubule membranes for electrochemical energy storage and production," Nature, vol. 393, no. 6683, pp. 346-349, 1998.

[16] E. Frackowiak and F. Béguin, "Carbon materials for the electrochemical storage of energy in capacitors," Carbon, vol. 39, no. 6, pp. 937-950, 2001.

[17] A. Züttel, Ch. Nützenadel, P. Sudan, et al., "Hydrogen sorption by carbon nanotubes and other carbon nanostructures," Journal of Alloys and Compounds, vol. 330-332, pp. 676-682, 2002.

[18] N. Nishimiya, K. Ishigaki, H. Takikawa, et al., "Hydrogen sorption by single-walled carbon nanotubes prepared by a torch arc method," Journal of Alloys and Compounds, vol. 339, no. 1-2, pp. 275-282, 2002.

[19] A. Züttel, P. Sudan, P. Mauron, T. Kiyobayashi, C. Emmenegger, and L. Schlapbach, "Hydrogen storage in carbon nanostructures," International Journal of Hydrogen Energy, vol. 27, no. 2, pp. 203-212, 2002.

[20] W. I. Milne, K. B. K. Teo, M. Chhowalla, et al., "Electron emission from arrays of carbon nanotubes/fibres," Current Applied Physics, vol. 2, no. 6, pp. 509-513, 2002.

[21] J. E. Jung, Y. W. Jin, J. H. Choi, et al., "Fabrication of triode-type field emission displays with high-density carbonnanotube emitter arrays," Physica B, vol. 323, no. 1-4, pp. 7177, 2002.

[22] J.-M. Bonard, M. Croci, C. Klinke, R. Kurt, O. Noury, and N. Weiss, "Carbon nanotube films as electron field emitters," Carbon, vol. 40, no. 10, pp. 1715-1728, 2002.

[23] Y. Saito and T. Yoshikawa, "Bamboo-shaped carbon tube filled partially with nickel," Journal of Crystal Growth, vol. 134, no. 1-2, pp. 154-156, 1993.

[24] Y. Saito, "Nanoparticles and filled nanocapsules," Carbon, vol. 33, no. 7, pp. 979-988, 1995.

[25] N. A. Kiselev, J. Sloan, D. N. Zakharov, et al., "Carbon nanotubes from polyethylene precursors: structure and structural changes caused by thermal and chemical treatment revealed by HREM," Carbon, vol. 36, no. 7-8, pp. 1149-1157, 1998.

[26] Y. Wen and Z. Shen, "Synthesis of regular coiled carbon nanotubes by Ni-catalyzed pyrolysis of acetylene and a growth mechanism analysis," Carbon, vol. 39, no. 15, pp. 2369-2374, 2001.

[27] Z. F. Ren, Z. P. Huang, J. W. Xu, et al., "Synthesis of large arrays of well-aligned carbon nanotubes on glass," Science, vol. 282, no. 5391, pp. 1105-1107, 1998.

[28] Ch. Täschner, F. Pácal, A. Leonhardt, et al., "Synthesis of aligned carbon nanotubes by DC plasma-enhanced hot 
filament CVD," Surface and Coatings Technology, vol. 174-175, pp. 81-87, 2003.

[29] C. F. Chen, C. L. Tsai, and C. L. Lin, "The characterization of boron-doped carbon nanotube arrays," Diamond and Related Materials, vol. 12, no. 9, pp. 1500-1504, 2003.

[30] C. H. Lin, S. H. Lee, C. M. Hsu, and C. T. Kuo, "Comparisons on properties and growth mechanisms of carbon nanotubes fabricated by high-pressure and low-pressure plasmaenhanced chemical vapor deposition," Diamond and Related Materials, vol. 13, no. 11-12, pp. 2147-2151, 2004.

[31] E. Gheeraert, N. Casanova, A. Tajani, et al., "n-type doping of diamond by sulfur and phosphorus," Diamond and Related Materials, vol. 11, no. 3-6, pp. 289-295, 2002.

[32] Ş. Erkoç, "Structural and electronic properties of bamboo-like carbon nanostructure," Physica E, vol. 31, no. 1, pp. 62-66, 2006.

[33] K. Uppireddi, A. González-Berríos, F. Piazza, B. R. Weiner, and G. Morell, "Effects of a nanocomposite carbon buffer layer on the field emission properties of multiwall carbon nanotubes and nanofibers grown by hot filament chemical vapor deposition," Journal of Vacuum Science and Technology B, vol. 24, no. 2, pp. 639-642, 2006.

[34] P. Ding, E. Liang, M. Chao, X. Guo, and J. Zhang, "Synthesis, characterization and low field emission of $\mathrm{CN}_{x}$ nanotubes," Physica E, vol. 25, no. 4, pp. 654-659, 2005.

[35] S. K. Srivastava, V. D. Vankar, D. V. Sridhar Rao, and V. Kumar, "Enhanced field emission characteristics of nitrogen-doped carbon nanotube films grown by microwave plasma enhanced chemical vapor deposition process," Thin Solid Films, vol. 515, no. 4, pp. 1851-1856, 2006.

[36] S. Gupta, B. L. Weiss, B. R. Weiner, and G. Morell, "Study of the electron field emission and microstructure correlation in nanocrystalline carbon thin films," Journal of Applied Physics, vol. 89, no. 10, pp. 5671-5675, 2001.

[37] G. Morell, A. González-Berríos, B. R. Weiner, and S. Gupta, "Synthesis, structure, and field emission properties of sulfurdoped nanocrystalline diamond," Journal of Materials Science, vol. 17, no. 6, pp. 443-451, 2006.

[38] A. González-Berríos, F. Piazza, and G. Morell, "Numerical study of the electrostatic field gradients present in various planar emitter field emission configurations relevant to experimental research," Journal of Vacuum Science and Technology B, vol. 23, no. 2, pp. 645-648, 2005.

[39] S. Gupta, B. R. Weiner, and G. Morell, "Synthesis and characterization of sulfur-incorporated microcrystalline diamond and nanocrystalline carbon thin films by hot filament chemical vapor deposition," Journal of Materials Research, vol. 18, no. 2, pp. 363-381, 2003.

[40] R. Haubner and D. Sommer, "Hot-filament diamond deposition with sulfur addition," Diamond and Related Materials, vol. 12, no. 3-7, pp. 298-305, 2003.

[41] A. Oberlin, "Carbonization and graphitization," Carbon, vol. 22, no. 6, pp. 521-541, 1984.

[42] N. Demoncy, O. Stéphan, N. Bran, C. Colliex, A. Loiseau, and H. Pascard, "Sulfur: the key for filling carbon nanotubes with metals," Synthetic Metals, vol. 103, no. 1-3, pp. 2380-2383, 1999.

[43] F. Tuinstra and J. L. Koenig, "Raman spectrum of graphite," The Journal of Chemical Physics, vol. 53, no. 3, pp. 1126-1130, 1970.

[44] T. W. Ebbesen, Carbon Nanotubes: Preparation and Properties, CRC Press, Boca Raton, Fla, USA, 1997.
[45] D. S. Knight and W. B. White, "Characterization of diamond films by Raman spectroscopy," Journal of Materials Research, vol. 4, no. 2, pp. 385-393, 1989.

[46] Y. Y. Wang, G. Y. Tang, F. A. M. Koeck, B. Brown, J. M. Garguilo, and R. J. Nemanich, "Experimental studies of the formation process and morphologies of carbon nanotubes with bamboo mode structures," Diamond and Related Materials, vol. 13, no. 4-8, pp. 1287-1291, 2004.

[47] G. Maurin, C. Bousquet, F. Henn, P. Bernier, R. Almairac, and B. Simon, "Electrochemical lithium intercalation into multiwall carbon nanotubes: a micro-Raman study," Solid State Ionics, vol. 136-137, pp. 1295-1299, 2000.

[48] Y. S. Jung and D. Y. Jeon, "Surface structure and field emission property of carbon nanotubes grown by radio-frequency plasma-enhanced chemical vapor deposition," Applied Surface Science, vol. 193, pp. 129-137, 2000.

[49] C. J. Lee and J. Park, "Growth model of bamboo-shaped carbon nanotubes by thermal chemical vapor deposition," Applied Physics Letters, vol. 77, no. 21, pp. 3397-3399, 2000.

[50] S. K. Srivastava, V. D. Vankar, D. V. Sridhar Rao, and V. Kumar, "Enhanced field emission characteristics of nitrogen-doped carbon nanotube films grown by microwave plasma enhanced chemical vapor deposition process," Thin Solid Films, vol. 515, no. 4, pp. 1851-1856, 2006.

[51] P. Ding, et al., defined the turn-on field as the field necessary to obtain a current density of $20 \mu \mathrm{A} / \mathrm{cm}^{2}$, so the turn-on field for a current density of $10 \mu \mathrm{A} / \mathrm{cm}^{2}$ must be less than $1.4 \mathrm{~V} / \mu \mathrm{m}$.

[52] M. Sveningsson, R.-E. Morjan, O. A. Nerushev, et al., "Raman spectroscopy and field-emission properties of CVD-grown carbon-nanotube films," Applied Physics A, vol. 73, no. 4, pp. 409-418, 2001.

[53] N.-S. Xu, Y. Chen, S.-Z. Deng, J. Chen, X.-C. Ma, and E.-G. Wang, "A new mechanism responsible for the enhancement of local electric field on the surface of emitting carbon nanotubes," Chinese Physics Letters, vol. 18, no. 9, pp. 12781281, 2001.

[54] N. S. Xu, Y. Chen, S. Z. Deng, J. Chen, X. C. Ma, and E. G. Wang, "Vacuum gap dependence of field electron emission properties of large area multi-walled carbon nanotube films," Journal of Physics D, vol. 34, no. 11, pp. 1597-1601, 2001.

[55] M. Liao, Z. Zhang, W. Wang, and K. Liao, "Field-emission current from diamond film deposited on molybdenum," Journal of Applied Physics, vol. 84, no. 2, pp. 1081-1084, 1998.

[56] A. N. Obraztsov and Al. A. Zakhidov, "Low-field electron emission from nano-carbons," Diamond and Related Materials, vol. 13, no. 4-8, pp. 1044-1049, 2004. 

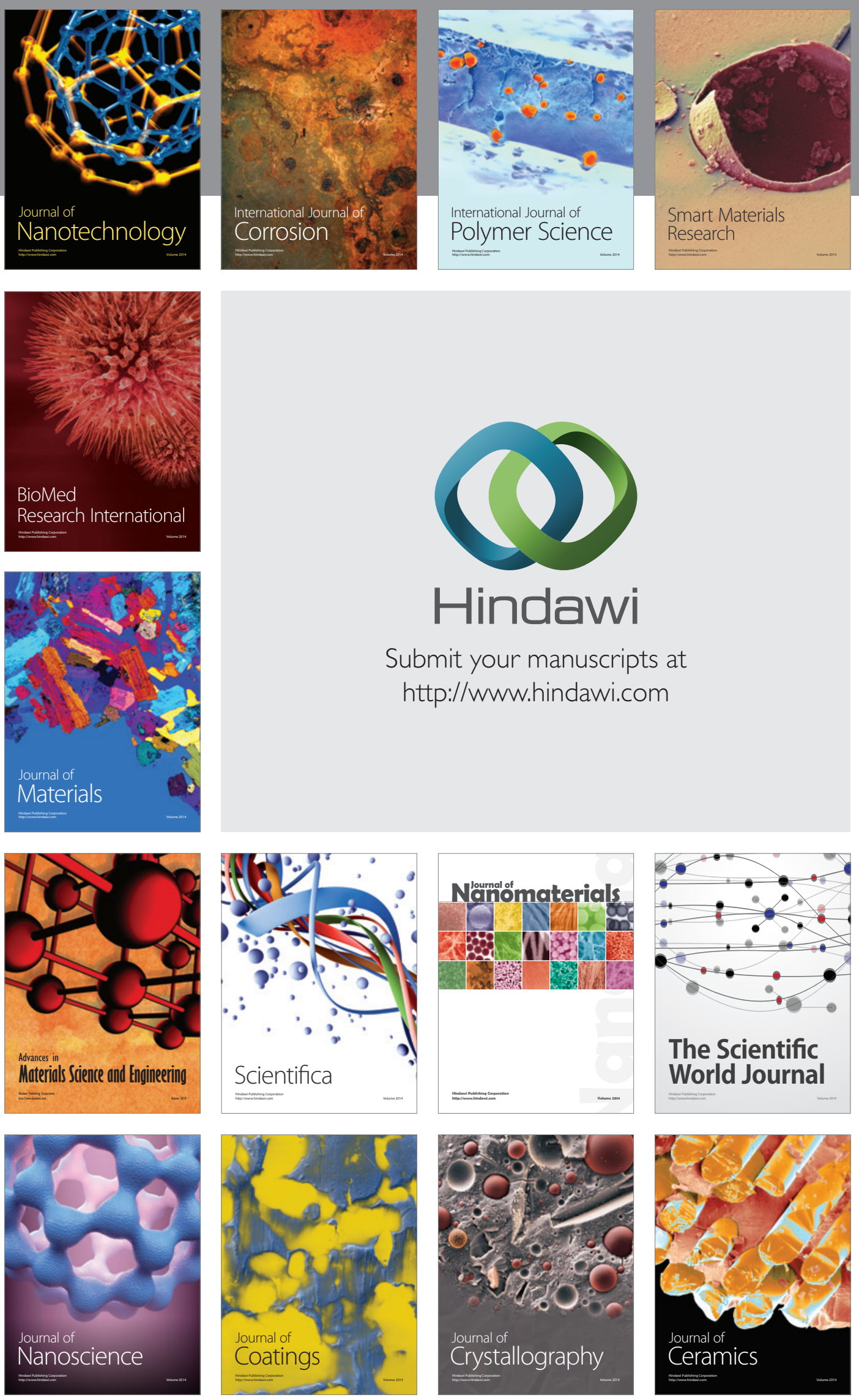

The Scientific World Journal

Submit your manuscripts at

http://www.hindawi.com

\section{World Journal}

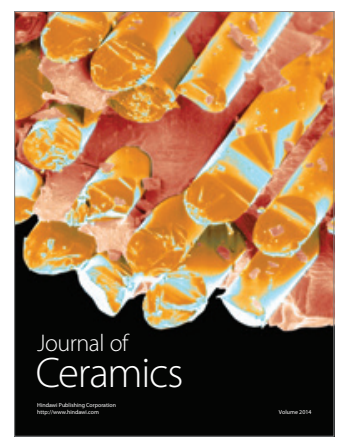

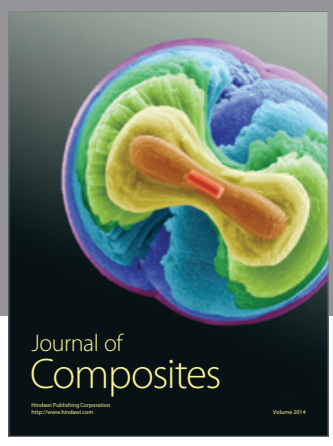
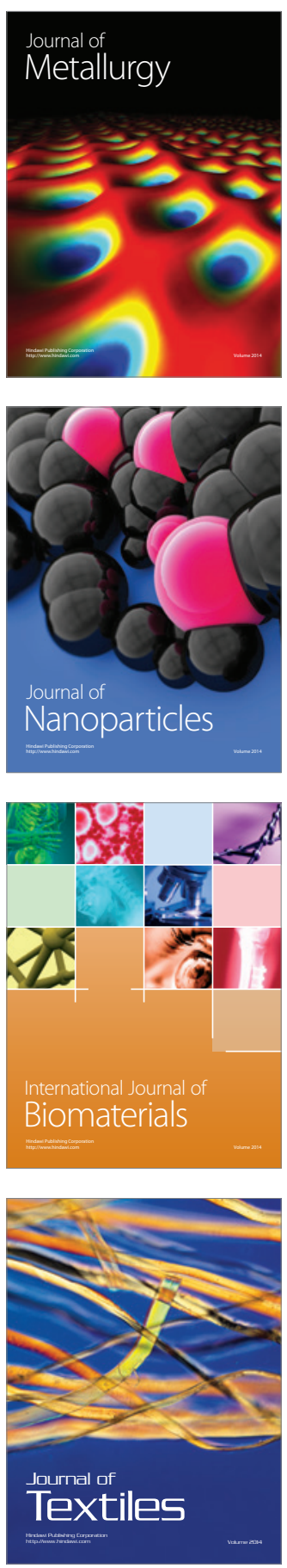